\title{
Santa Efigenia / Ifigenia: hagiografía y mito en San Mateo en Etiopia, de Felipe Godínez ${ }^{1}$
}

\author{
Esther Márquez \\ Universidad de Sevilla \\ emarquez3@us.es
}

Recepción: 23/02/2017, Aceptación: 13/07/2017, Publicación: 22/12/2017

\section{Resumen}

Este artículo aborda el estudio de las fuentes de San Mateo en Etiopía, obra que lleva a las tablas la vida del apóstol San Mateo, centrándose en el episodio de la evangelización de Etiopía y la conversión al cristianismo de Santa Efigenia, la hija del rey Egipo. Mediante el examen de sus fuentes, tanto hagiográficas como mitológicas, se pretende demostrar la contaminación que lleva a cabo Godínez entre la historia de Santa Efigenia y el mito de Ifigenia, la hija de Agamenón. El estudio comparativo de estos dos intertextos ayuda a comprender mejor el proceso de escritura de Godínez y su manera de fusionar hagiografía y mito.

Palabras clave

Felipe Godínez; teatro; hagiografía; mitología; Ifigenia; Siglo de Oro

\begin{abstract}
Saint EphigenialIphigenia: Hagiography and myth in San Mateo en Etiopía by Felipe Godinez

This article addresses the study of the sources of San Mateo en Etiopia by Felipe Godínez. This play focuses on Saint Matthew's life, especially on his evangelization
\end{abstract}

1. Este artículo forma parte de mi proyecto de tesis doctoral financiado gracias a la ayuda para contratos predoctorales de Formación del Profesorado Universitario (FPU 15/02570) del Ministerio de Educación, Cultura y Deporte, y respaldado por el proyecto de investigación Del Sujeto a la Institución Literaria en la Edad Moderna (FFI 2014-54367-C2-2-R). Me gustaría agradecer a los profesores Juan Montero Delgado y Piedad Bolaños Donoso sus comentarios y sugerencias, que sin duda han mejorado este trabajo. 
of Ethiopia and Saint Ephigenia's conversion to Christianity. The examination of both its hagiographical and mythological sources shows that Godínez blends the stories of Saint Ephigenia and Iphigenia (Agamenon's daughter). This comparative analysis reveals the interweaving between myth and hagiography and Godínez's writing process.

\section{Keywords}

Felipe Godínez; theatre; hagiography; mythology; Iphigenia; Spanish Golden Age

Menéndez Pelayo en sus Estudios y discursos de critica histórica y literaria (1941) dedica una de sus conferencias sobre Calderón a analizar la importancia y la función de la mitología en sus autos sacramentales:

Mucho más común, aunque hoy nos parezca irreverente, era el auto sacramental fundado en la mitología [...]. Como quiera que sea, repito que la razón de este simbolismo está perfectamente explicada por Calderón en un diálogo entre el judaísmo y el gentilismo con que comienza El sacro Parnaso, y por su lectura veremos que la mitología es considerada por Calderón — de igual modo que el judaísmo- como una preparación para la ley de gracia. (Menéndez Pelayo 1941: 145)

La fusión entre mitología y cristianismo juega, así, un papel esencial dentro del mundo literario calderoniano (Páramo Pomareda 1957; Neumeister 2000; Arellano 2011), pero no es el único autor que emplea este recurso. Felipe Godínez, por ejemplo, también cultivó este esquema teatral al incluir muchos elementos mitológicos en sus comedias hagiográficas y veterotestamentarias. La concepción de la mitología griega como un paso previo del cristianismo, de la que hablaba Menéndez Pelayo, casa bien con la mentalidad de Godínez, judío converso cercano a los movimientos iluministas sevillanos, como se recoge en su Auto de Fe de 1624 (Menéndez Onrubia 1985). 
El objetivo de este artículo es el análisis de las fuentes de San Mateo en Etiopía, obra que lleva a las tablas la vida del apóstol San Mateo, centrándose en el episodio de la evangelización de Etiopía y la conversión al cristianismo de Santa Efigenia, la hija del rey Egipo. Mediante el examen de sus fuentes, tanto hagiográficas como mitológicas, se pretende demostrar la contaminación que lleva a cabo Godínez entre la historia de Santa Efigenia y el mito de Ifigenia, la hija de Agamenón. El estudio comparativo de estos dos intertextos ayudará a comprender mejor el proceso de escritura de Godínez y su uso de la fusión entre hagiografía y mito, y, al mismo tiempo, ilustrará desde una perspectiva concreta la nueva cosmovisión del Barroco español. Asimismo, este trabajo dejará patente la actualización barroca del mito de Ifigenia, lo que demuestra la vitalidad del mito y la pervivencia de la heroína griega dentro de la Literatura Española, pues, al fin y al cabo, «lo que caracteriza el mito es sobre todo su aptitud para ser contado y repetido" (Burkett 2013: 65).

Para llevar a cabo este análisis, en primer lugar, aislaremos los motivos hagiográficos presentes en la obra de Godínez y buscaremos las similitudes de esa obra con las distintas versiones de la hagiografía de la santa etíope procedentes de los legendarios ${ }^{2}$ modernos. En segundo lugar, se procederá a estudiar las fuentes mitológicas mediante la identificación de los motivos comunes entre la comedia de Godínez y el mito de Ifigenia. Por último, se estudiará el proceso de imbricación entre materia hagiográfica y materia mitológica en la obra.

\section{San Mateo en Etiopía y sus fuentes hagiográficas}

San Mateo en Etiopía probablemente fue escrita en 1635, según los datos que ha aportado Bolaños Donoso (1983). ${ }^{3}$ Pertenece al grupo de las comedias hagiográficas, que junto a las veterotestamentarias, conforman el mayor grupo de obras de su producción. Esta comedia dramatiza la vida del apóstol San Mateo desde el momento en el que decide partir a evangelizar Etiopía hasta su enfrentamiento con Hirtaco, hermano del rey. En la primera jornada, ya en el país africano, San Mateo se encuentra con el rey Egipo, que había decidido sacrificar a su primogénita, Ifigenia, para calmar a los dragones que estaban asolando su reino. ${ }^{4}$ San Mateo logra que los dragones huyan, pero no consigue detener el sacrificio, ya que el sacerdote Arfaxad había convencido al rey de que la muerte

2. Siguiendo la bibliografía científica sobre este tema, se utiliza el término legendario con la acepción de compilación de vidas de santos.

3. Para la datación de esta comedia, Bolaños Donoso (1983) se basa en un manuscrito de la Biblioteca Nacional de Madrid, fechado en 1635, y en el análisis estilométrico que sitúa la obra entre 1630-1635 por el abundante uso de romances. La primera impresión que se conoce de la obra es de 1667 en Parte veinte y ocho de comedias nuevas de los mejores ingenios desta corte, Madrid: Joseph Fernández de Buendía.

4. A lo largo de todo el Siglo de Oro, hay una gran variabilidad del antropónimo. No es rara la alternancia entre Efigenia/ Ifigenia, no solo para la santa sino también para la hija de Agamenón. 
de su hija lo volvería inmortal. Sin embargo, al comienzo de la segunda jornada, gracias a la intervención divina de Jesús, Ifigenia logra escapar de las llamas. Tras su salvación, la joven decide hacer voto de castidad y convertirse en abadesa de un convento. En la tercera jornada, el rey Egipo muere y sube al trono Hirtaco, que desea casarse con Ifigenia. Para ello, trata de seducirla de distintos modos, pero sus deseos se ven frustrados por la intervención de San Mateo.

Teniendo en cuenta los motivos hagiográficos en torno a los que se articula esta comedia (el episodio de los dragones, la conversión al cristianismo de Ifigenia, su voto de castidad y los intentos frustrados de seducción de Hirtaco), puede postularse que la fuente principal de Godínez fue alguna de las hagiografías modernas de San Mateo y Santa Ifigenia, puesto que en las fuentes hagiográficas antiguas (Orígenes, Eusebio de Cesarea o Sócrates de Constantinopla) no aparecen tratados estos temas. ${ }^{5}$ Bolaños Donoso (1983) ha planteado la posibilidad de que Felipe Godínez conociese de primera mano la vida de San Mateo a través de la Legenda aurea o el Flos sanctorum de Villegas. En España, la Legenda aurea se transmitió, fundamentalmente, a través de dos familias de compilaciones de vidas de santos (la Compilación B y la Compilación $A)^{6}$, basadas en dos traducciones parciales de la obra de Varazze y que, además, fueron «adornadas con otros materiales de origen diverso» (Aragüés 2012: 350), como se observa en los distintos manuscritos bajomedievales conservados hasta nuestros días. A lo largo del siglo Xvi, ambas familias tuvieron un importante éxito editorial gracias a la publicación de varios Flores sanctorum basados en estos manuscritos.

La Compilación $B$ tuvo dos vías de difusión editorial desde finales del siglo Xv. En primer lugar, de esta familia deriva un incunable, el Flos Sanctorum con sus etimologías, ${ }^{7}$ cuyo compilador corrigió los materiales de la Compilación B mediante cotejo del texto original de la Legenda aurea, y además añadió nuevos capítulos. En segundo lugar, también a partir de esta familia, se publicó la $L e$ yenda de los santos que vulgarmente flossantorum llaman, que contó con diversas reimpresiones y revisiones a lo largo del siglo xvi. ${ }^{8}$ Por su parte, la Compilación $A$

5. Por otra parte, el proceder de otros dramaturgos coetáneos al seguir los santorales de su tiempo reforzaría esta hipótesis.

6. Estudiadas por Walsh y Thompson (1986-1987) que, tras analizar los santorales castellanos medievales, llegaron a la conclusión de que existían dos grandes familias: la Compilación B, que parece más temprana, y la Compilación A. La primera, a su vez, presenta dos redacciones diferentes: la versión $B 1$ y la versión B2 (Aragüés 2016).

7. Cuenta con una edición crítica de Cortés Guadarrama de 2010.

8. «Tenemos noticias de unas doce impresiones de la obra entre 1490 y 1575, aunque tan solo se conserva ejemplar de la mitad de ellas» (Aragüés 2016: 150). Las ediciones que se conservan de esta obra son: Burgos, Juan de Burgos, ¿1497-1500?, hoy en la British Library; Sevilla, Juan Varela de Salamanca, ca. 1520-1521, hoy en el Archivo Histórico del Santuario de Loyola; Toledo, Juan Ferrer, 1554, hoy en Bayerische Staats Bibliothek; Revisión del Dr. Majuelo, Alcalá de Henares, Sebastián Martínez, 1567, hoy en Národní knihovna en Praga; Sevilla, Juan Gutiérrez, 1568 hoy en la Bibliteca Nacional; y Sevilla, Alonso de la Barrera, 1579, hoy en la Balliol College Library en Oxford (Aragüés 2016: 174). 
dio a las prensas el Flos sanctorum renacentista, cuya autoría se atribuye tanto a Pedro de la Vega como a Gonzalo de Ocaña, y que también fue editado y revisado en distintas ocasiones a lo largo del siglo (Aragüés 2012).

El fin editorial de estos legendarios, que dejaron de publicarse hacia $1580,{ }^{9}$ se produjo tras la aparición de una nueva generación de Flores sanctorum (Aragüés 2014). La publicación en 1575 de la colección latina de vidas de santos Vitae sanctorum de Lippomano, revisada por Surio, supuso un hito en este género editorial, ya que respondía a las nuevas exigencias de los lectores, que pedían una mayor verosimilitud y una renovación del género, en consonancia con la nueva mentalidad postridentina. ${ }^{10}$ Siguiendo la estela de la obra de Lippomano y Surio, en 1578, Villegas publicó la primera parte de su Flos sanctorum, que tuvo otras cinco partes más (la última publicada en 1603). Por su parte, en 1599, el padre Ribadeneyra dio a la prensa el primer volumen de su Flos sanctorum. Como señala Aragüés, frente a los viejos santorales, "los legendarios postridentinos se sustentan en una exigente búsqueda de la verdad y el rigor hagiográficos» (Aragüés 2014: 35).

Todos estos santorales impresos en el siglo xvi incluyen la leyenda de San Mateo y Santa Efigenia, por lo que, en principio, Godínez pudo haber consultado cualquiera de ellos. Cabe destacar el caso del Flos sanctorum de Villegas, ya que, frente al resto de Flores que solo incluyen esta hagiografía una vez, esta obra contiene tres capítulos, repartidos en los distintos volúmenes, de la vida de la santa etíope. El primer capítulo se inserta en la festividad de San Mateo (parte primera), al igual que en el resto de legendarios; el segundo se encuentra en el tomo dedicado a los sermones (cuarta parte), donde se ensalza la vida de San Mateo como ejemplo de virtud; y el tercero aparece en la quinta parte de la obra, dedicada a los exempla, donde la historia de Ifigenia se desgaja de la de San Mateo y adquiere total independencia, al presentar a la joven como ejemplo de castidad. A pesar de las diferencias en cuanto a su presentación, los tres capítulos de la obra de Villegas comparten los mismos elementos esenciales. En resumen, Godínez pudo emplear como fuente principal de su comedia una de las siguientes obras: la Leyenda de los santos, el Flos sanctorum renacentista, el Flos sanctorum de Villegas y el Flos sanctorum de Ribadeneyra. ${ }^{11}$

9. No obstante, este hecho no supuso el fin de su influencia debido a los ejemplares que se conservaron en bibliotecas privadas.

10. Como muestra de este cambio de pensamiento sirva como ejemplo la censura del padre Alonso de Sandoval a La hagiografía y vidas de los santos de Juan Basilio Sanctoro: «[...] y hallo contener lección muy pía, y en cuanto se ha podido muy auténtica, cosa muy deseada por acá, por cuanto hay muchas cosas muy apócrifas en los libros de vidas de santos que hasta agora se han impreso en romance, lo cual hace no dar crédito aún a las muy ciertas y averiguadas [...]» (Sanctoro, 15: fol. 4r). Para este artículo, se ha adoptado el criterio de modernizar la acentuación y la ortografía de los textos para facilitar la lectura de ellos.

11. Sin embargo, parece poco probable que consultase la Vitae sanctorum (1595) de Lippomano y Surio, ya que esta obra no contiene elementos significativos comunes con la comedia de Godínez. Esta versión no incluye el episodio de los dragones, y de la vida de Ifigenia solo recoge el deseo que sentía Hirtaco por ella, la oposición de San Mateo a esta boda y su posterior asesinato. 
Para poder determinar cuál de entre estas obras es la fuente principal de Godínez, hemos aislado los principales motivos hagiográficos de la comedia: 1) aparición de los dragones y su posterior expulsión por parte de San Mateo, 2) primer sermón de San Mateo, 3) reto entre San Mateo y los hechiceros para resucitar a un muerto, 4) estancia de San Mateo en casa del eunuco de la reina Candace, ${ }^{12}$ 5) uso de la hechicería para doblegar la voluntad de Ifigenia y que renuncie a su voto de castidad, 6) levantamiento del pueblo contra Hirtaco, 7) reinado de la hermana de Ifigenia tras la muerte de Hirtaco, y 8) el hecho de que San Mateo no había predicado en ningún sitio antes de llegar a Etiopía.

De todos estos motivos, solo el primero (la aparición de los dragones y su expulsión) y el cuarto (la estancia en casa del eunuco) aparecen en todos las versiones de la leyenda. El segundo elemento (el primer sermón de San Mateo) permite arrojar cierta luz sobre la fuente consultada por Godínez. En su San Mateo en Etiopía, el apóstol, una vez que se encuentra con la familia real etíope, ofrece un sermón al pueblo en el que trata el tema del paraíso. Tanto la Leyenda de los Santos como el Flos sanctorum renacentista recogen el tema del paraíso como tema principal del sermón de San Mateo. Por el contrario, en los santorales de Villegas y de Ribadeneyra, San Mateo predica sobre el misterio de la Encarnación y la bienaventuranza de los santos. La diferencia del tema del sermón es un primer indicio para pensar que Godínez no utilizó los legendarios postridentinos, pero no es el único. El quinto motivo, el uso de la hechicería para doblegar la voluntad de Ifigenia, tampoco aparece en las obras de Villegas ni de Ribadeneyra, y sí en la Leyenda de los Santos y en el Flos Sanctorum renacentista. Lo mismo sucede con el octavo motivo (los lugares que evangelizó San Mateo). En Villegas y en Ribadeneyra, San Mateo había predicado ya a los hebreos y a los egipcios antes de llegar a Etiopía, mientras que en la Leyenda de los Santos y en el Flos Sanctorum renacentista, Etiopía es el primer lugar en el que predica el apóstol. Además de todos estas diferencias entre la comedia de Godínez y los legendarios de Villegas y Ribadeneyra, este último presenta aún más variantes. En la versión de Ribadeneyra, tampoco aparecen los motivos del levantamiento del pueblo contra Hirtaco, ni el reinado de la hermana de Ifigenia después de su derrocamiento, mientras que en Villegas, en la Leyenda de los Santos y en el Flos Sanctorum renacentista sí aparecen ambos.

Las concomitancias entre la comedia y la Leyenda de los Santos y el Flos Sanctorum renacentista apuntan a que Godínez pudo haber consultado estas obras, que no tienen apenas diferencias entre sí, salvo el motivo de la expulsión de los

12. La historia de la conversión de la reina Candace se narra en Hechos 8:27. Algunos autores han defendido que fue el eunuco el que evangelizó Etiopía: «Several accounts have been preserved of the conversion of Ethiopia to Christianity. There is a legend to the effect that it was evangelized in Apostolic times by Queen Candace's eunuch, who, according to the New Testament, was baptized by Philip the deacon. Origen, however, says that St. Matthew was the apostle to the Ethiopians, but the story is not considered at all authentic» (Mercer 1915: 83). 
dragones. ${ }^{13}$ En el Flos Sanctorum renacentista, los dragones se duermen cuando ven a San Mateo:

Y estando el apóstol diciendo esto, vino uno que le dijo que venían los encantadores, y traían dos dragones que echaban fuego y piedra azufre por la boca y por las narices, y mataban a todos los hombres. Y el apóstol, oyendo esto, hizo la señal de la cruz en su frente, y en la boca, y en sus pechos, y salió muy seguro a ellos. Y viéndolo, los dragones vinieron, y echáronse a sus pies, y durmiéronse. (Vega 1580: fol. CCXV v)

En cambio, en la Leyenda de los Santos, los dragones mueren en cuanto ven al apóstol, y San Mateo reta a los magos a que los resuciten. Cuando queda patente que los hechiceros no tienen suficiente poder, San Mateo les devuelve la vida y los dragones, ya amansados, regresan al desierto de donde procedían.

Entonces, vino uno y dijo que vinieran los magos con dos dragones que echaban de sus narices y de sus bocas llamas de piedra zufre, y que mataban todos los hombres; y el apóstol, santiguándose, salió seguro contra ellos. Y luego que le vieron, los dragones cayeron muertos ante él, y dijo a los magos: «Oh, encantadores, ¿̨do es la vuestra arte? Hacedles vivir si pudieredes. Y es cierto que en vos se hubiera cumplido lo que vos pensasteis hacer a mí, sino porque yo rogué a nuestro señor Jesucristo que no vos hiciese mal». Entonces, mandó a los dragones que se fuesen, y luego se levantaron, y se fueron y no hicieron mal alguno [...]. (Ferrer 1554: fol. crlij)

En la obra de Godínez, aparecen combinados los motivos del reto entre San Mateo y los magos y de la resurrección, aunque el objeto de la resurrección no sean los dragones sino una de las hijas del rey. Una vez que se ha desvelado que Arfaxad, el mago, se quedaba con las ofrendas rituales del dios Bel, cae en desgracia ante el rey Egipo. A pesar de ello, el rey todavía no tiene claro a quién debe creer, por lo que San Mateo y Arfaxad deciden que aquel que logre devolverle la vida a un muerto, tendrá el favor del rey:

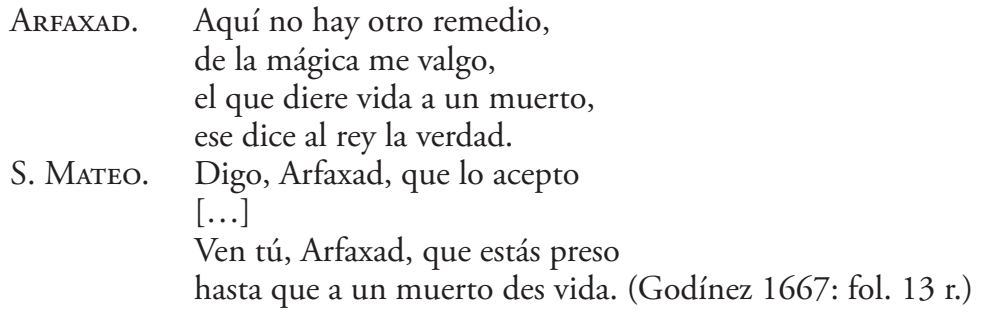

13. Ni en Villegas $(1589,1591,1998)$ ni en Ribadeneyra (1604) aparece este motivo. En estos legendarios, los dragones son expulsados por San Mateo sin más dilación. 
Así pues, la Leyenda de los Santos y la obra de Godínez comparten el motivo del reto de la resurrección entre San Mateo y los magos como medio para dilucidar quién representa a la verdadera religión, por más que el objeto de la resurrección se haya desplazado en la obra de Godínez por razones dramáticas. Además, no es el único rasgo que vincula la Leyenda de los Santos con la comedia de Godínez. A diferencia del resto de las obras analizadas, la Leyenda de los Santos termina con tres exempla de abandono del pecado y conversión, protagonizados por San Pablo, David y San Mateo:

Y esto es que dice San Juan que tres maneras son de pecado: ca hay pecado de soberbia, y pecado de lujuria, y pecado de avaria [sic. por avaricia] y en el primero pecó San Pablo, ca perseguía mucho la iglesia de Dios, que son los cristianos; y en el segundo pecó David, ca hizo adulterio, y, después, mató a Urías, su caballero muy fiel; y en el tercero pecó San Mateo, ca, por razón de avaricia, hacía muchas malas ganancias, ca él estaba en el puerto del mar y tomaba los derechos de las naves. Y como quier que estos tres hombres fueron pecadores, plugo mucho a Dios con la su penitencia, ca no solamente los perdonó Dios las culpas, mas antes les dió muchas gracias y dones [...] y a San Mateo hizo apóstol y evangelista. Y por ende, leemos los dichos libros destos tres más que de todos los otros, porque ningún hombre ni mujer por pecador que sea no debe desesperar de la misericordia de Dios, pues que tales gracias y tan grandes hubieron tales pecadores como estos. (Ferrer 1554: fol. crliij)

\section{Y estas mismas razones aparecen al comienzo de San Mateo en Etiopia:}

$\begin{array}{ll}\text { ÁNGEL } & \text { Gran coronista Mateo, } \\ & {[\ldots]} \\ & \text { el rezo más ordinario } \\ & \text { habrá de ser tu evangelio, } \\ & \text { las epístolas de Pablo } \\ & \text { y los salmos de David, } \\ & \text { porque todos tres sois santos } \\ & \text { que antes fuisteis pecadores. (Godínez 1667: fol. 1r.) }\end{array}$

Este pasaje podría explicar las motivaciones de Godínez para hacer una comedia hagiográfica con San Mateo como protagonista, ${ }^{14}$ ya que responde a una

14. Bolaños Donoso ya había reflexionado sobre estas posibles motivaciones: «Pero, ¿̨ué es lo que lleva a Felipe Godínez a tomar a San Mateo como núcleo central de una de sus obras? Es difícil dar respuesta exacta, pero sí podemos pensar en una posible hipótesis: simpatía personal hacia este santo en particular, con el que podía compararse en su forma de vida. En un principio es publicano, pertenece al mundo de los gentiles; le llega después una llamada y se convierte para dedicarse al apostolado y morir mártir, incomprendido y fuera de su patria. Además está considerado como el patrón de los 'Changeurs', recaudadores de impuestos, de los contables, de los aduaneros..., profesiones liberales y relacionadas directamente con los quehaceres del mundo judío, y ipor qué no simpatizar con su patrón?» (Bolaños Donoso 1983: 358). 
de las características fundamentales de su teatro: la conversión del pecador o el pagano (Bolańos Donoso 1983; Vega García-Luengos 1993).

Tras el análisis y comparación de los motivos hagiográficos esenciales de San Mateo en Etiopía con los legendarios más importantes de la época, parece plausible postular que Godínez utilizó como fuente principal la Leyenda de los Santos. Además de los numerosos motivos hagiográficos presentes en las dos obras, ambas comparten la idea fundamental de que el arrepentimiento del pecador conlleva no solo el perdón de Dios sino también la gracia divina. ${ }^{15}$

\section{Elementos mitológicos en la obra de Godínez}

En su comedia, Godínez combinó las fuentes hagiográficas con el mito griego de Ifigenia, que conocía, probablemente, no solo por la gran difusión del mito durante el Siglo de Oro, sino también a partir de las fuentes originales. ${ }^{16}$

Existen dos versiones fundamentales del mito, que se nos han transmitido por dos tragedias de Eurípides: ${ }^{17}$ "Ifigenia en Áulide», que se centra en el episodio del sacrificio, e "Ifigenia entre los Tauros», que narra los sucesos que siguieron al sacrificio y su posterior reencuentro con su hermano, Orestes. Godínez sigue la primera de estas versiones, ${ }^{18}$ como demuestran los elementos que aparecen en su comedia:

1. Las causas de la ira del dios son desconocidas.

2. El oráculo que afirma que solo la muerte de Ifigenia puede calmar la ira del dios.

3. La aceptación por parte del rey de su obligación para con su pueblo, independientemente de sus intereses como padre.

4. El sacrificio de la joven.

5. La aceptación voluntaria de Ifigenia.

6. La salvación de la joven por parte de un dios.

15. Frente a ello, los legendarios de Villegas y Ribadeneyra presentan bastantes diferencias con respecto a la comedia de Godínez. Por otra parte, aunque tiene muchas concomitancias, el Flos Sanctorum renacentista no incluye el reto entre San Mateo y el mago Arfaxad.

16. No hay que olvidar que Godínez cursó estudios superiores en el Colegio Mayor de Santa María de Jesús de Sevilla, donde recibió una formación humanística que se percibe a lo largo de toda su obra. 17. A partir de las dos obras de Eurípides surgen dos versiones del mito que han tenido una larga trayectoria dentro de la literatura occidental y que han sido tratadas por una amplia diversidad de autores, desde Ovidio hasta Racine. En este trabajo, las obras de Eurípides irán en cursiva (ej.: Ifigenia en Aulide) mientras que las versiones del mito irán entrecomilladas («Ifigenia en Áulide»). 18. Por ello, no parece posible que, a la hora de redactar San Mateo en Etiopía, se basase en la Ifigenia entre los Tauros de Eurípides, ni en Epitome de Apolodoro, ni en De officiis de Cicerón, que emplea el mito como ejemplo de que en ocasiones es mejor no cumplir una promesa. Tampoco en el De rerum natura de Lucrecio, obra en la que se lleva a cabo una dura crítica a las religiones. Tampoco parece posible que Godínez se basase en el fragmento dedicado a este mito en el Capitulo de Boscán, pues en esta versión Ifigenia acaba muriendo. Todas estas obras, aunque tratan el mito de Ifigenia, recogen versiones distintas con elementos muy diferentes de los que aparecen en San Mateo en Etiopía. 
Los primeros motivos que aparecen en la comedia de Godínez que pueden vincularse con la materia mitológica son la ira del dios y el oráculo. Tanto el dios Bel de San Mateo en Etiopía como Ártemis en el mito griego castigan al pueblo. Para aplacar la ira del dios, los gobernantes se ven obligados a consultar un oráculo, que dictamina, en ambos casos, que la única solución es sacrificar a la primogénita del rey:

ArfaXad. El oráculo dice que, hasta tanto que al Dios aplaque con su muerte propia Ifigenia — abrasada en su amor santo, porque ha de ser el fénix de Etiopialos dragones serán horror y espanto

[...] de horrible magnitud, de forma fiera, a cuyos riesgos, dice el dios, te expones, hasta que el fénix o Ifigenia muera [...]. (Godínez 1667: fol. 2r.)

Tanto en la versión del mito que recoge «Ifigenia en Áulide» como en la comedia de Godínez, el sacrificio de la joven tiene el objetivo de resolver una situación problemática de la nación sobre la que gobierna su padre. Mientras que en el mito griego la muerte de Ifigenia sirve para permitir que los barcos zarpen rumbo a Troya, en la obra de Godínez funciona, en primera instancia, como único método de expulsar a los dragones que amenazan Etiopía. Ante el dilema de permitir el sacrificio de su hija para salvar a su pueblo, tanto Agamenón como Egipo reaccionan de la misma manera. A pesar de que ambos progenitores se ven embargados por un gran sentimiento de culpa a la hora de tomar la decisión, los dos arguyen que su deber como reyes es más importante que la vida de sus hijas.

Otro motivo que se repite en ambas obras es la aceptación de las jóvenes de su destino. En la comedia de Godínez, Ifigenia se deja conducir voluntariamente al sacrificio. A pesar de que acaba de convertirse al cristianismo (todavía es catecúmena), la joven está resuelta a morir si Dios así lo desea, y no alberga ningún tipo de temor:

San Mateo. No desmayes, Ifigenia.

IfigENIA. Mateo, yo moriré alegre en presencia tuya. (Godínez 1667: fol. 9r)

La Ifigenia griega también acepta de buen grado su sacrificio, ya que desea lograr el bien de su Estado y de su propia casa, pues cree que, con la guerra de Troya, su padre logrará la tan ansiada fama. Irónicamente, su muerte funcionará como detonante de los acontecimientos representados en la Orestíada de Esquilo. ${ }^{19}$

19. Esquilo en su Agamenón pone en boca de Casandra estas palabras: «iA una casa que odian los dioses, testigo de innúmeros crímenes en los que se asesinan parientes, se cortan cabezas, a una casa que es matadero de hombres y a un solar empapado en sangre!» (Esch. Ag. 1090). 
No obstante, a pesar de las similitudes entre el mito y la obra de Godínez, el motivo del sacrificio cumple papeles muy distintos, debido al diferente contexto sociocultural que rodea a ambas obras. Desde el punto de vista de la sociedad griega, el sacrificio, generalmente de animales, está intrínsecamente relacionado con la piedad para con los dioses y funciona como núcleo de muchos actos rituales. Aunque los sacrificios de seres humanos no eran ya habituales en Época Arcaica o Clásica, los mitos en los que aparecen sacrificios humanos son muy numerosos:

[...] dans le mythe, le sacrifice humain est un acte accompli dans des situations chaotiques où les valeurs traditionnelles politiques, sociales, religieuses, pour résumer l'harmonie cosmique entre hommes et dieux, sont battues en brèche. (Bonnechère 2009: 195)

Así, el sacrificio de Ifigenia se inserta dentro de una tradición específica de inversión de las reglas socio-culturales griegas, en la situación de caos y de excepcionalidad que precede al asalto de Troya por las tropas griegas: «En el ámbito griego, el sacrificio de vírgenes caracteriza sobre todo la preparación para la guerra» (Burkert 2013: 114).

Sin embargo, en el contexto sociocultural de la Contrarreforma, el valor del sacrificio toma un cariz diferente. La idea del sacrificio de Cristo, íntimamente ligada a la polémica sobre la doctrina de la justificación, juega un papel esencial a partir del Concilio de Trento, que fomenta las historias de mártires cristianos. En el caso de la Ifigenia de Godínez, la aceptación de su destino se asocia a sus inquietudes espirituales y a su deseo de servir a la "causa de las causas todas" (Godínez 1667: fol. 3v), en consonancia con las motivaciones de muchos mártires cristianos. De esta manera, Godínez mantiene el esquema que repite a lo largo de todo su teatro hagiográfico:

Se trata de demostrar el cambio de vida que se produce en sus protagonistas. De una forma de vida desarraigada, pecadora o pagana, se llega a una vida pura, cristiana, incluso a la santidad [...] el protagonista pasa, tras el arrepentimiento de sus pecados, al estado de santidad. (Bolańos Donoso 1983: 680)

La idea de la trasformación espiritual que sufren los personajes de Godínez viene subrayada en San Mateo en Etiopía mediante la alegoría del ave fénix, que recorre toda la obra. A Ifigenia se la compara con un fénix, pues su bautizo se presenta como un renacer, idea que se corresponde con las tesis tridentinas. Esta idea, además, ratifica los intereses sociales de Godínez, ya que, si mediante el bautizo se empezaba una vida nueva, los orígenes familiares de cada uno no tenían importancia, y su pasado de judeoconverso no debería suponer ninguna traba social durante el siglo XVII.

Por último, cabe destacar la salvación de Ifigenia. En ambos casos, un dios (Ártemis según la tradición grecolatina; Cristo para Godínez), se apiada de la 
joven gracias a su decisión voluntaria de aceptar el sacrificio, y hace que se eleve en el cielo y desaparezca, impidiendo, así, su muerte. Octavio Paz afirmaba que, en el teatro barroco español, «la verdadera libertad se ejerce sometiéndose a Dios» (Paz 2010: 211). Ifigenia alcanza su plenitud como personaje al aceptar su sacrificio, y por su fe en Cristo, se salva.

La presencia de todos estos elementos en San Mateo en Etiopía indica que Godínez tuvo en cuenta el mito de Ifigenia para la configuración de su obra. Gracias al análisis de los motivos mitológicos de la comedia, es posible afirmar que se basa en la versión del mito de «Ifigenia en Áulide», como demuestran la presencia del sacrificio de la joven, su aceptación voluntaria y su posterior salvación a manos de un dios que se apiada de ella.

\section{La imbricación de la materia hagiográfica y mitológica}

Godínez funde la materia hagiográfica y la mitológica a través de un entramado de diversos motivos. Desde el punto de vista estructural, los distintos niveles dramáticos se fusionan gracias a dos nexos de unión: en primer lugar, el hecho de que Ifigenia tenga que ser sacrificada para evitar que los dragones asolen el reino; en segundo lugar, se aúnan a través de la conversión de Ifigenia y su voto de castidad.

El episodio del sacrificio de la joven es esencial para entender el proceso de imbricación que lleva a cabo Godínez, ya que en este pasaje se mezclan materiales de distintas procedencias. Por un lado, de la tradición hagiográfica toma el motivo de los dragones. Por otro, el tema del castigo divino y el sacrificio de una virgen para restaurar el orden cósmico procede del mito griego. La mezcla de ambos motivos en la obra crea un nuevo esquema (el sacrificio de una joven a un monstruo) que no estaba presente ni en la hagiografía ni en el mito de Ifigenia. Este nuevo planteamiento de Godínez podría ser fruto de su propia imaginación. Sin embargo, el estudio de las fuentes mitológicas parece apuntar en otra dirección. En la Filosofía secreta de Pérez de Moya aparece el mito de Ifigenia inserto dentro del mito de Andrómeda. En esta obra, se narra cómo Júpiter castiga a Casiopea, madre de Andrómeda, por su soberbia. Para ello, manda que la joven Andrómeda sea encadenada a una roca como sacrificio a una bestia marina. A partir de ese momento, Pérez de Moya explica a sus lectores que los sacrificios humanos eran una costumbre relativamente común en la Antigüedad, aduciendo como ejemplo el sacrificio de Ifigenia. El hecho de que en esta obra la mención del sacrificio de Ifigenia se inserte dentro del mito de Andrómeda, donde se lleva a cabo el sacrificio de la primogénita de un rey para calmar a un monstruo que ha sido enviado como castigo de un dios, nos hace pensar que Godínez pudo conocer la obra de Pérez de Moya. ${ }^{20}$

20. Además de esta peculiaridad, tanto San Mateo en Etiopía como la narración del mito de Ifigenia de la Filosofía secreta comparten otros motivos. En ninguno de los dos textos se ofrecen 
El segundo elemento que une la hagiografía y el mito es la conversión de santa Ifigenia. Mientras que en la tradición hagiográfica, la joven es un personaje pasivo que se convierte al cristianismo gracias a los milagros que obraba San Mateo, en la comedia de Godínez, Ifigenia es un personaje activo que toma sus propias decisiones. Este cambio profundo en la psicología del personaje se produce gracias a que la joven se enfrenta a una serie de dilemas morales que Godínez incorpora en San Mateo en Etiopía mediante los motivos procedentes de la tradición mitológica. Por un lado, la presencia del sacrificio supone un punto de inflexión para la transformación espiritual de Ifigenia, ya que pone a prueba su fe y muestra su disposición de servicio a dios, al aceptar sin reticencias su propia muerte. Por otra parte, el motivo mitológico de la salvación de un dios, en este caso Jesucristo, determina su vocación monástica. El deseo de mantener su voto de castidad se ha enraizado tan fuerte en su psique que la lleva, al final de la obra, a enfrentarse directamente con Hirtaco, su antiguo prometido y nuevo rey. De esta manera, al incluir los elementos mitológicos en San Mateo en Etiopía, Godínez logra que el personaje de Ifigenia adquiera una nueva profundidad psicológica, que no estaba presente en la tradición hagiográfica, al pasar de ser un carácter secundario que se dejaba llevar por las determinaciones que otros tomaban por ella a convertirse en un personaje que decide sobre su propia vida y persevera en sus resoluciones, incluso si ello supone enfrentarse a Hirtaco o incluso a la muerte.

En relación con este último punto, es esencial también comentar el motivo de la virginidad. La virginidad es un elemento fundamental tanto en el mito griego como en la hagiografía, y cumple, asimismo, un importante papel dentro de la obra de Godínez. Por una parte, para la mentalidad católica, la santidad femenina está íntimamente ligada a la virginidad, y así se ilustra en la parte quinta del Flos sanctorum de Villegas, donde la historia de Santa Ifigenia sirve como exemplum en el capítulo dedicado a la castidad. Por otra parte, en el contexto sociocultural griego el rito del sacrificio se equipara, en muchas ocasiones, con el rito del matrimonio de las jóvenes vírgenes. En el mundo griego, Eros y Thánatos eran dos divinidades que, con frecuencia, aparecían estrechamente ligadas. En muchos textos griegos se produce la mezcla de los dos campos semánticos: por ejemplo, los himeneos se contraponen a los cantos fúnebres; las antorchas de la boda, a la pira funeraria; o las ofrendas florales de ambos ritos se equiparan. Entre este tipo de paralelismos, uno de los más comunes es el que se establece entre el lecho nupcial y

explicaciones racionales sobre las causas de la ira del dios, y en ambos se indica que solo el sacrificio de la primogénita calmará su ira. Asimismo, la reacción del Agamenón de Pérez de Moya comparte muchos rasgos con el Egipo de Godínez, como su gran sentido del deber para con su pueblo. Junto a estos rasgos, en la versión de Pérez de Moya también llama la atención la crítica a los sacrificios humanos y la explicación que de ellos hace. Según Pérez de Moya, los antiguos hacían muchos sacrificios humanos a distintos ídolos debido a la influencia del demonio, de forma bastante similar a lo que enuncia San Mateo cuando van a sacrificar a Ifigenia. 
la tumba. ${ }^{21}$ La cercanía que se establecía entre ambos conceptos dentro del ámbito griego también aparece en los ritos sacrificiales. En el mito griego, la sangre que se derrama sobre la piedra sacrificial simboliza la ruptura del himen en la noche de bodas, tal y como ha comentado Elsa Rodríguez:

[...] cuando el coro nota cuánta sangre de la garganta del bonito cuerpo de Ifigenia manchará el altar de Ártemis (vv.1514-1517) está reactualizando la centralidad de la posesión y violación del cuerpo virginal en ambos ritos del matrimonio y de la ejecución sacrificial. (Rodríguez Cidre 2015: 118-119)

En el caso de la San Mateo en Etiopía, si por una parte, Godínez resalta la santidad de Ifigenia por medio de su virginidad a la manera de las hagiografías, por otra parte, siguiendo la tradición mitológica griega, su disposición a ser sacrificada se equipara a una especie de boda con Dios. Esta equivalencia resulta clara, en palabras del propio Jesús, tras la salvación de la joven.

Jesús. Mateo, Ifigenia es esta,

ya mi esposa y capitana.

En milicia, soberana

de vírgenes que me apreste,

porque, huyendo inconvenientes

del mundo, en más dulces bodas,

serán religiosas todas,

pobres, castas, y obedientes.

De tálamo tan dichoso

soy dueño yo; tú, tercero.

Yo, el esposo verdadero;

tú, el amigo del esposo. (Godínez 1667: fol. 9v- fol.10r.)

De nuevo, la fusión de la hagiografía y el mito cumple un propósito en la comedia de Godínez. La virginidad de su protagonista no solo funciona como muestra de su santidad a la manera de la tradición hagiográfica sino que también sirve como elemento de unión entre los ritos del sacrificio y el matrimonio. Al establecer este nexo, Godínez subraya la espiritualidad de su protagonista y su renuncia voluntaria al mundo terrenal, lo que refuerza su rechazo a las continuas proposiciones de Hirtaco (el conflicto principal de la comedia) y resalta el debate final entre San Mateo y el antiguo prometido de Ifigenia sobre el sacramento del matrimonio.

21. Valga como ejemplo este epigrama: «¿Dónde está la dulce fuerza de la amada sabiduría, injusta Cloto? ¿Dónde ese afán mío por servir a las Musas Piérides? Aún tengo doce años y ya yazgo bajo tierra en el penoso Hades, sin cumplir la deuda que con mis padres tenía. En vez del tálamo nupcial y los sagrados himeneos tengo una tumba, una estela y el odioso polvo» (Barrio Vega 1992: 53). 


\section{Conclusiones}

En suma, cabe resaltar el interés que presenta el estudio, por un lado, de las fuentes hagiográficas y, por otro, de los materiales mitológicos de San Mateo en Etiopía. Tras el análisis de los motivos hagiográficos de la comedia queda patente que la Leyenda de los Santos es el Flos sanctorum que más semejanzas comparte con la obra de Godínez. No solo presentan los mismos elementos temáticos, sino que también aparece, en ambas obras, el esquema de la conversión del pecador a santo, que tanta importancia tiene dentro de la poética godiniana. La presencia del esquema de pecado/ arrepentimiento/ buen cristiano, fundamental en Godínez (Bolaños Donoso 1983), sugiere que la huella de este legendario podría ser todavía más profunda en su obra teatral. Bajo esta nueva óptica, tal vez, estudios posteriores puedan arrojar una nueva luz sobre la influencia de este Flos a lo largo de su obra y su pervivencia en otras comedias hagiográficas del autor de Moguer.

Asimismo, el análisis de San Mateo en Etiopía pone de relieve la importancia de la contaminación de materiales mitológicos y hagiográficos en la obra de Godínez. El caso de San Mateo en Etiopía vendría a confirmar las aportaciones de Albuixech (2010) a propósito de Los trabajos de Job, y las de Cortés Hernández (2003) a propósito de Celos son bien y ventura, ${ }^{22}$ y que el uso de la fusión de materiales no es un caso aislado en su obra, sino que, al contrario, es uno de los recursos que caracterizan su teatro hagiográfico y veterotestamentario. ${ }^{23} \mathrm{Sin}$ embargo, no hay que olvidar que este tipo de imbricaciones se insertan dentro un marco general mucho más amplio y que incluye a otros dramaturgos del teatro áureo como Lope de Vega (Sánchez Aguilar 2010) o Calderón (Páramo Pomadera 1957; Neumeister 2000). Godínez contribuye, entonces, a esta práctica teatral de fusión de mitos grecolatinos y de vidas de santos que recorrió todo el Siglo de Oro español.

22. Godínez, en Los trabajos de Job, crea un personaje, Astrea, que no remite a la tradición bíblica, sino a la mitología griega. Astrea, en la obra de Godínez, es la sobrina de Job. La elección de su nombre sirve para reforzar la historia del profeta, pues Astrea desaparece de la escena en el momento en el que Job empieza a padecer sus infortunios y vuelve a escena una vez que su tío ha mejorado su estado inicial. Este hecho subraya, primero, el paso de una «edad de oro» en la vida de Job a un estado de caos, y la vuelta a la normalidad al final de la obra. De esta manera, «Godínez conjuga en la obra conocidos mitos bíblicos y paganos que subrayan la idea de los vaivenes de la fortuna y la periodicidad de los ciclos históricos» (Albuixech 2010: 178). Asimismo, Cortés Hernández ha analizado la importancia del tema edípico en la construcción de la comedia Celos son bien y ventura, obra que también presenta tintes hagiográficos al tratar del mártir San Albano: «No se trata de una comedia de santos, sino de una reelaboración de la tragedia edípica para ser representada en el ámbito cristiano» (Cortés Hernández 2003: 79).

23. Godínez también emplea la mitología griega para subrayar la caracterización de algunos personajes, como sucede en El soldado del cielo: San Sebastián en la que los personajes del Infante Carlos y su criado Gandalín se asemejan a Eneas y Acates (Bolańos Donoso 1983: 225). 


\section{Bibliografía}

S.A., Leyenda de los santos, Toledo: en casa de Juan Ferrer, 1554, ubicado en Bayerische Staatsbibliothek en München con signatura 2 V. ss. c. 71.

Albuixech, Lourdes, "Astrea en Los trabajos de Job, de Felipe Godínez», Anagnórisis, 2 (2010), 162- 181.

AragüÉs, José, «Los Flores Sanctorum medievales y renacentistas. Brevísimo panorama crítico", eds. Natalia Fernández Rodríguez y María Fernández Ferreiro, Literatura medieval y renacentista en España: lineas y pautas, Salamanca, SEMYR, 2012, 349-361.

—, "La difusa autoría del Flos Sanctorum. Silencios, presencias, imposturas", ed. Maud Le Guellec, El autor oculto en la literatura española. Siglos XIV a XVIII, Madrid, Casa de Velázquez, 2014, 21-40.

—, «La Leyenda de los santos: orígenes medievales e itinerario renacentista», Memorabilia, 18 (2016), 133-187.

Arellano, Ignacio, «El motivo del viaje en los autos sacramentales de Calderón, I: los viajes mitológicos», Revista de literatura, 73, 145 (2011), 165-182.

Barrio Vega, María Luisa del (ed.), Epigramas funerarios griegos, Madrid, Gredos, 1992.

Bolaños Donoso, Piedad, La obra dramática de Felipe Godinez (trayectoria de un dramaturgo marginado), Sevilla, Diputación Provincial, 1983.

Bonnechère, Pierre, «Le sacrifice humain grec entre norme et anormalité», en $L a$ norme en matière religieuse en Grèce ancienne, ed. P. Brulé, Liège: Centre International d'Étude de la Religion Greque Antique, 2009, 189-212.

Burkert, Walter, Homo Necans. Interpretaciones de ritos sacrificiales y mitos de la antigua Grecia, trad. Marc Jiménez Buzzi, Barcelona, Acantilado, 2013.

Cortés Guadarrama, Marcos Ángel, El 'Flos sanctorum con sus ethimologias'. Edición y estudio, tesis doctoral dirigida por Fernando Baños Vallejo, Universidad de Oviedo, 2010.

Cortés Hernández, Santiago, «Vida de San Albano: herencia del teatro del Siglo de Oro en los pliegos de cordel», Revista de Literaturas Populares, III, 2 (2003), 73-91.

Esquilo, Agamenón, en Tragedias, introducción general de Manuel FernándezGaliano, trad. y notas de Bernardo Perea Morales, Madrid, Gredos, 1986.

Eusebio de Cesarea, Historia eclesiástica, texto, versión española, introducción y notas por Argimiro Velasco-Delgado, Madrid, Biblioteca de Autores Cristianos, 2008.

Godínez, Felipe, San Mateo en Etiopía, en Parte veinte y ocho de Comedias nuevas de los mejores ingenios desta Corte [...], Madrid, por José Fernández de Buendía: acosta de la viuda de Francisco de Robles, 1667, 371-402, ubicada en la Biblioteca Nacional con signatura R/22681.

Lippomano, Aloysio y Surio, Laurentio, Vitae Sanctorum, Lyon, por Franciscum Haraeum, 1595, ubicado en la Universidad de Sevilla con signatura A 23/3/08. 
Menéndez Onrubia, Carmen, «Aspectos narrativos en la obra dramática de Felipe Godínez», Criticón, 30 (1985), 201-223.

Menéndez Pelayo, Marcelino, "Autos sacramentales. Conferencia tercera» en Estudios y discursos de crítica histórica y literaria. III (Teatro: Lope, Tirso, Calderón), ed. Enrique Sánchez Reyes, Madrid, Consejo Superior de Investigaciones Científicas, 1941.

Mercer, Samuel A. B., The Ethiopic Liturgy. Its Sources, Development, and Present Form, Milwaukee-London, The Young Churchman Company/ A. R. Mowbray \& Company, 1915.

Neumeister, Sebastian, Mito clásico y ostentación. Los drama mitológicos de Calderón, trads. Eva Reichenberger y Juan Luis Milán, Kassel, Reichenberger, 2000.

Páramo Pomadera, Jorge, "Autos sacramentales' de Calderón de la Barca», Thesaurus, XIII (1957), 51-80.

Paz, Octavio, El arco y la lira, México D.F., Fondo de Cultura Económica, 2010.

Pérez de Moya, Juan, Filosofía secreta [...], Madrid, en casa de Francisco Sánchez, 1585, ubicado en la Universidad de Sevilla con signatura A Res. $76 / 4 / 17$.

Ribadeneyra, Pedro de, Flos sanctorum [...], Madrid, Luis Sánchez, 1604, ubicado en la Biblioteca Alessandrina de Roma con signatura G i 26/ LA $0010140191 \mathrm{v}$.

Rodríguez Cidre, Elsa, "Maneras rituales de matar a una doncella: Ifigenia entre las víctimas sacrificiales euripideas», coords. Ana Iriarte y Luísa de Nazaré Ferreira, Coimbra, Idades e género na literatura e na arte da Grécia antiga, Imprensa da Universidade de Coimbra y Annablume, 2015.

Sánchez Aguilar, Agustín, Lejos del Olimpo: el teatro mitológico de Lope de Vega, Cáceres: Universidad de Extremadura. Servicio de Publicaciones, 2010.

SANCtoro, Ioan Basilio, La hagiografía y vidas de los santos [...], Bilbao, por Matías Mares, 1580, ubicado en la Universidad de Sevilla con signatura A Res. 60/1/07.

Sócrates de Constantinopla, Histoire ecclésiastique. I, trads. Pierre Périchon y Pierre Maravall, París, Éditions du Cerf, 2003.

Vega García-Luengos, Germán, «Experiencia personal y constantes temáticas de un escritor judeoconverso: Felipe Godínez (1585-1659), en Proyección histórica de España en sus tres culturas, Castilla y León, América y el Mediterráneo, coord., Eufemio Lorenzo Sanz, Medina del Campo, Junta de Castilla y León, Consejería de Cultura y Turismo, 1993, 579-588.

Vega, Pedro de la, Flos sanctorum renacentista, Sevilla: en casa de Fernando Díaz a costa de Francisco de Cisneros, 1580, ubicado en la Biblioteca Nacional en Madrid con signatura R/39517.

Villegas, Alonso, Flos sanctorum, Toledo, en casa de la viuda de Juan Rodríguez, 1591, ubicado en la Biblioteca Alessandrina de Roma con signatura G i 21. 
—, Flos sanctorum cuarta y última parte [...], Madrid, en casa de Pedro Madrigal, 1589, ubicado en la Universidad de Sevilla con signatura A Res. 78/3/06.

-, Fructus Sanctorum y quinta parte del Flos sanctorum, edición digital realizada por José L. Canet a partir de la edición de José Aragüés Aldaz, Revista Lemir, 2, 1998. 